\section{Commentary: The not-so-basic bicuspid}

\author{
Dawn S. Hui, MD
}

The simplistic definition of bicuspid aortic valve (BAV) as a semilunar valve with 2 leaflets belies the complexity of this condition. Despite being the most common cardiac valvular abnormality, BAV in many ways remains a mystery. The underlying molecular mechanisms, genetic, and epigenetic phenomena of nonsyndromic BAV and associated aortopathy remain areas of ongoing investigation. In parallel to the deepening scientific understanding of these areas, surgeons have led the way to a more comprehensive understanding of the anatomy of the aortic valve and root in BAV. This is necessary to address the surgical challenges of correcting what is not a uniformly phenotypic expression.

While all BAV have in common 2 leaflets, it is a variable condition, with phenotypic variation in leaflet morphology, cusp fusion length, commissure height, and commissural angles. In this edition of Techniques, Woo and colleagues ${ }^{2}$ elegantly demonstrate these anatomic relationships in the varying subtypes of BAV. Much as advanced imaging techniques such as echocardiography and computed tomography have informed our knowledge of BAV anatomy, this videographic, although simple, adds a layer of understanding that may inform aortic valve repair techniques. Of particular relevance is the implication for valve-sparing root replacement in Sievers type I BAV. Whether to maintain the native commissural orientation or to place the commissures at a $180^{\circ} / 180^{\circ}$ versus native orientation remains an area of investigation. Unequal commissure heights have implications for reimplantation, and the degree of cusp

From the Department of Cardiothoracic Surgery, Joe R. and Teresa Lozano Long School of Medicine, UT Health San Antonio, San Antonio, Tex.

Disclosures: The author reported no conflicts of interest.

The Journal policy requires editors and reviewers to disclose conflicts of interest and to decline handling or reviewing manuscripts for which they may have a conflict of interest. The editors and reviewers of this article have no conflicts of interest.

Received for publication July 31, 2021; revisions received July 31, 2021; accepted for publication Aug 3, 2021; available ahead of print Aug 8, 2021.

Address for reprints: Dawn S. Hui, MD, 7703 Floyd Curl Dr, Suite 211L, San Antonio, TX 78229 (E-mail: huid@uthscsa.edu).

JTCVS Techniques 2021;9:48

2666-2507

Copyright (C) 2021 The Authors. Published by Elsevier Inc. on behalf of The American Association for Thoracic Surgery. This is an open access article under the CC BY-NCND license (http://creativecommons.org/licenses/by-nc-nd/4.0/).

https://doi.org/10.1016/j.xjtc.2021.08.011

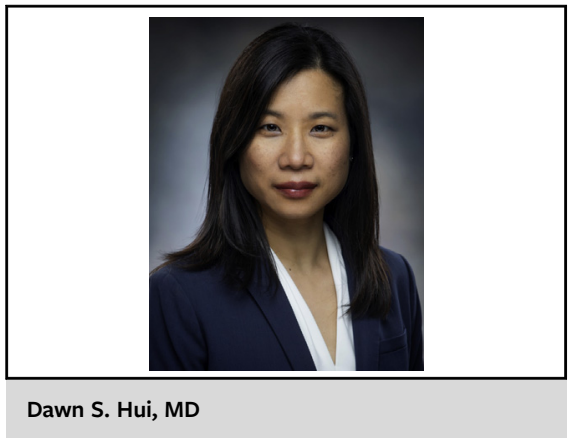

CENTRAL MESSAGE

Much as advances in clinical imaging have informed surgical approaches, innovative visual educational tools are useful to enhance understanding of bicuspid aortic valve structural relationships.

fusion affects native leaflet quality and mobility. ${ }^{3,4}$ Finally, although the video depicts the structural relationships, it does not portray important aspects of pathology, such as leaflet prolapse or important tenets of repair such as effective height. However, it provides a solid foundation and framework on which surgeons and scholars of bicuspid aortic valve disease can begin to understand such matters.

\section{References}

1. Jahanyar J, El Khoury G, de Kerchove L. Commissural geometry and cusp fusion insights to guide bicuspid aortic valve repair. J Thorac Cardiovasc Surg Tech. 2021;7:83-92.

2. Woo YJ, Paulsen MJ, de Kerchove L, Zhu Y. Videographic conceptual dynamic representation of bicuspid aortic valve anatomic configurations and structural inter-relationships. J Thorac Cardiovasc Surg Tech. 2021;9:44-5.

3. Siki MA, Habertheuer A, Bavaria JE, Komlo C, Hunt M, Freas MA, et al. Two different geometric orientations for aortic neoroot creation in bicuspid aortic valve repair with root reimplantation. J Thorac Cardiovasc Surg. 2020;160:47-57.

4. Vallabhajosyula P, Szeto WY, Komlo CM, Ryan LP, Wallen TJ, Gorman RC, et al. Geometric orientation of the aortic neoroot in patients with raphed bicuspid aortic valve disease undergoing primary cusp repair and a root reimplantation procedure. Eur J Cardiothorac Surg. 2014;45:174-80. 